\title{
ELECTROCHEMICAL PERFORMANCE OF LITHIUM-NICKEL OXIDE THIN FILMS OBTAINED WITH USE OF ATOMIC LAYER DEPOSITION
}

\author{
${ }^{1}$ Yury KOSHTYAL, ${ }^{1}$ Ilya EZHOV, ${ }^{1}$ llya MITROFANOV, ${ }^{1}$ Artem KIM, 1,2Denis NAZAROV, \\ ${ }^{1,3}$ Alexander RUMYANTSEV, ${ }^{1}$ Anatoly POPOVICH, ${ }^{1}$ Maxim MAXIMOV \\ ${ }^{1}$ Peter the Great Saint-Petersburg Polytechnic University, Saint-Petersburg, Russian Federation, \\ maximspbstu@mail.ru \\ ${ }^{2}$ Saint-Petersburg State University, Saint-Petersburg, Russian Federation, \\ dennazar1@yandex.ru \\ ${ }^{3}$ loffe Institute, Saint-Petersburg, Russian Federation, \\ rumyantsev.amr@gmail.com
}

https://doi.org/10.37904/nanocon.2019.8612

\begin{abstract}
Present work is dedicated to the development of lithium-nickel oxide film - positive electrode for solid-state lithium-ion batteries. The formation of electrochemical phase was performed by a two-step process. At first lithium-nickel oxide film was deposited by Atomic Layer Deposition on stainless steel 316SS and silicon wafer at $300{ }^{\circ} \mathrm{C}$. One "supercycle" of lithium-nickel oxide film consisted of n (5 or 10) cycles of nickel oxide structures (NiOx) deposition, followed by one cycle of lithium oxide (LiOx) structures deposition. Bis(cyclopentadienyl)nickel(II) $\left(\mathrm{NiCp}_{2}\right)$ and Lithium bis(trimethylsilyl)amide (LiHMDS) were used as metal precursors. Oxygen remote plasma was applied as a counter-reagent (oxidizer). The thickness of deposited films was $58.2 \mathrm{~nm}(\mathrm{n}=10,250$ supercycles) and $74.3 \mathrm{~nm}(\mathrm{n}=5,500$ supercycles). At the second step, the obtained films were annealed in an air atmosphere at different temperatures $400-800{ }^{\circ} \mathrm{C}$ for $10-15$ minutes. Spectral ellipsometry, small-angle X-ray scattering, X-ray diffraction were used to characterize obtained films. The electrochemical performance was studied with the use of Cyclic Voltammetry and Galvanostatic cycling. The discharge capacity augmented with an increase of a fraction of NiOx structures and annealing temperature. The highest capacity $\left(23 \mu \mathrm{Ah} \cdot \mu \mathrm{m}^{-1} \cdot \mathrm{cm}^{-2}\right.$, at $7.4 \mathrm{C}$ rate) was observed for sample calcined at $800{ }^{\circ} \mathrm{C}(\mathrm{n}=10,250$ supercycles).
\end{abstract}

Keywords: Solid-state lithium-ion batteries, positive electrode, atomic layer deposition, lithium-nickel oxide

\section{INTRODUCTION}

Lithium-ion batteries (LIBs) are widely used to power portative electronics, electric vehicles, and can be applied for new miniature devices such as sensors and specialized medical equipment [1]. The decrease of portative lithium-ion batteries volume leads to an augmentation of inactive battery materials content and therefore decline of energy density is observed. One of the ways to overcome this challenge is to produce thin batteries with the use of film deposition methods applied in electronics such as chemical vapor deposition [2], magnetron sputtering [3], atomic layer deposition (ALD) [4-6], etc. ALD is used for the synthesis of oxides, sulfides, nitrides, etc. and is based on self-terminating chemical reactions with surface functional groups and allows to control chemical content and thickness of deposited film $[7,8]$.

In recent studies, the synthesis by ALD method and electrochemical properties of lithium cobalt oxide [4,5] and lithium manganese oxide was discussed [6]. Lithium nickel oxide-based cathode materials are applied to fabricate LIBs with a high specific energy. The main advantages of these materials are high average discharge voltage and capacity, which augments with nickel content. The deposition of film containing three elements can be conducted with the use of "supercycles" which include cycles. For instance, one supercycle of lithium nickel oxide deposition can consist of $n$ cycles of nickel oxide and $m$ cycles of lithium oxide deposition. Review 
of synthesis conditions and list of precursors used for nickel and lithium-containing films can be found elsewhere $[9,10]$. Since cathode materials for lithium batteries possess crystal structure, a thermal treatment may be needed to crystalize deposited films.

\section{MATERIALS AND METHODS}

Monocrystalline silicon wafers (surface orientation 111, diameter $40 \mathrm{~mm}$, Svetlana Co., LTD, Saint-Petersburg, Russia) and stainless-steel plates (316SS, Tob New Energy Technology Co., LTD, diameter $15.8 \mathrm{~mm}$ ) were used as substrates. Before deposition, silicon substrates were cleaned in an ultrasonic bath in acetone and deionized water for $15 \mathrm{~min}$.

The deposition of lithium nickel oxide ( $\mathrm{Li}-\mathrm{Ni}-\mathrm{O}$ ) films was conducted by ALD method with the use of Picosun $\mathrm{R}-150$ setup at $300{ }^{\circ} \mathrm{C}$ and at a base pressure in the reactor of 8-12 hPa. Lithium hexamethyldisilazide (LiHMDS, 97\%, Sigma Aldrich) and bis(cyclopentadienyl)nickel (II) (NiCp2, 99\% Sigma-Aldrich) were used as metal-containing reagents. Remote oxygen plasma applied as a counter-reactant. The supercycle started with 5 or 10 nickel oxide structures (Ni-O, n) cycles deposition followed by one cycle of lithium oxide structures ( $\mathrm{Li}-\mathrm{O}, \mathrm{m}$ ) deposition. The conditions of $\mathrm{Li}-\mathrm{O}$ and $\mathrm{Ni}-\mathrm{O}$ deposition were selected considering results reported elsewhere [10,11]. Deposition of lithium oxide system: $\mathrm{T}_{\text {source }}-160{ }^{\circ} \mathrm{C}$; pulse/purge with $\mathrm{N}_{2} /$ remote $\mathrm{O}_{2}$ plasma pulse/purge with $\mathrm{N}_{2}-0.1 / 6 / 15 / 6 \mathrm{~s}$. Deposition of nickel oxide system: $\mathrm{T}_{\text {source }}-110{ }^{\circ} \mathrm{C}$; pulse/purge with $\mathrm{N}_{2} /$ remote $\mathrm{O}_{2}$ plasma pulse/purge with $\mathrm{N}_{2}-1 / 10 / 15 / 10$ s. Synthesized samples were heated in an oven for 10 minutes, at $400-800{ }^{\circ} \mathrm{C}(\mathrm{T})$. The samples are denoted according to following form of designation Li-Ni-O m/n T.

The thicknesses of the films were measured by spectral ellipsometry $(350-1000 \mathrm{~nm})$ using Ellips-1891 SAG ellipsometer (CNT, Novosibirsk, Russia). The growth rates were calculated from thickness measured by scanning ellipsometry.

X-ray reflectometry $(X R R)$ and $x$-ray diffraction $(X R D)$ studies in surface-sensitive grazing incidence XRD (GIXRD) modes were performed using a Bruker D8 DISCOVER (Cu-K $\alpha$, Billerica, MA, USA) high-resolution diffractometer. The obtained results were processed by the Rietveld method using TOPAS 5 software (XRD) and by the simplex method using LEPTOS 7.7 (XRR).

For electrochemical studies performed in CR2032 coin cells. The samples of Li-Ni-O deposited on the 316SS surface were used. Lithium foil, polyolefin porous film 2325 (Celgard, Charlotte, NC, USA), and TC-E918 (Tinci, Guangzhou, China) solution were used as the counter electrode, separator, and electrolyte, respectively. Coin cells were assembled in an argon glove box OMNI-LAB (VAC). Cyclic voltammetry (CV) was performed using a potentiostat PGSTAT302N+ (Autolab, Utrecht, the Netherlands) in the range of $2.5-4.3 \mathrm{~V}$ with a scan rate of $0.5 \mathrm{mV} / \mathrm{s}$. Cyclic charge/discharge was performed using the battery testing system CT-3008W-5V10mA (Neware, Shenzhen, China) at room temperature in the potential range of 2.5-4.3 V, at current 20-80 $\mathrm{AA}$.

\section{RESULTS AND DISCUSSION}

\subsection{Films deposition and thermal treatment}

According to previous studies, the growth rate of lithium oxide, nickel oxide structures at deposition conditions used in the present paper (Table 1) are $\approx 0.16 \mathrm{~nm} /$ cycle [11] and $0.01 \mathrm{~nm} /$ cycle [10], correspondingly. Lithium may evaporate during calcination at higher temperatures [12], and this effect might be more pronounced for thin films. Thus, the number of nickel oxide structures deposition in supercycle was chosen to provide the lithium excess in deposited films. Two series of films were deposited Li-Ni-O 1/5 and Li-Ni-O 1/10 (Table 2). The growth rate of $\mathrm{Li}-\mathrm{Ni}-\mathrm{O}$ films was lower than the linear combination of growth rates of lithium oxide and nickel oxide structures. The decrease of growth rate per supercycle may be due to application of $\mathrm{NiCp}_{2}$ 
relatively big molecule that can lead to a decline of reactive hydroxyl groups concentration because of steric hinderance [13].

Table 2 Number of cycles, thickness and average growth rate during deposition of Li-Ni-O films

\begin{tabular}{|c|c|c|c|c|c|}
\hline Name & Nsc & Nc & $\begin{array}{c}\text { Thickness, } \\
\text { nm }\end{array}$ & GPsc & GPC \\
\hline Li-Ni-O 1/5 & 500 & 3000 & $74.0-74.5$ & 0.1485 & 0.0247 \\
\hline Li-Ni-O 1/10 & 250 & 2750 & $56.9-59.4$ & 0.2326 & 0.0211 \\
\hline
\end{tabular}

During the investigation by XRD of lithium oxide and nickel oxide structures [10] deposited separately in conditions used in the present research, the presence of crystal phases was found. A pronounced peak of $\mathrm{Li}_{2} \mathrm{CO}_{3}$ phase was observed in the diffractograms of uncoated lithium oxide film by alumina due to its reaction with air atmosphere. The $\mathrm{NiO}_{2}$ crystal structure peaks were determined on diffractograms. Since both $\mathrm{Li}-\mathrm{Ni}-\mathrm{O}$ $1 / 5$ and $\mathrm{Li}-\mathrm{Ni}-\mathrm{O} 1 / 10$ samples were amorphous, the addition of nickel oxide deposition to the synthesis program of lithium oxide may stabilize the obtained lithium oxide structures and hinder their interaction with air atmosphere. On the other hand, adding lithium oxide structures deposition prevent nickel oxide crystallization.

According to XRR results, the Li-Ni-O 1/10 film composed of two layers (Table 3). The outer layer is thin and less dense than a layer adjacent to the substrate. Low roughness and the gradient of density (upper, bottom) are observed for both layers. The average density is closer to the density of lithium oxide $\left(2.01 \mathrm{~g} / \mathrm{cm}^{3}\right)$ than to the density of lithium nickel oxide $\left(4.64 \mathrm{~g} / \mathrm{cm}^{3}\right)$ and nickel oxide $\left(6.6 \mathrm{~g} / \mathrm{cm}^{3}\right)$. Thus the low-density lithiumcontaining phase prevails in the volume of the deposited thin film.

Table 3 Li-Ni-O 1/10 film parameters measured by XRR

\begin{tabular}{|c|c|c|c|c|}
\hline \multirow{2}{*}{ Material } & \multirow{2}{*}{ Thickness, $\mathbf{n m}$} & \multirow{2}{*}{ Roughness, $\mathbf{n m}$} & \multicolumn{2}{|c|}{ Density, $\mathbf{g} / \mathbf{c m}^{\mathbf{3}}$} \\
\cline { 3 - 5 } & & & Upper & Bottom \\
\hline Phase 1 & 5.19 & 2.39 & 2.26 & 1.20 \\
\hline Phase 2 & 38.5 & 1.19 & 2.58 & 2.96 \\
\hline $\mathrm{Si}$ & - & - & 2.33 & 2.33 \\
\hline
\end{tabular}

After calcination of $\mathrm{Li}-\mathrm{Ni}-\mathrm{O}$ at $700{ }^{\circ} \mathrm{C}$ during 10 minutes, the low-intensity reflections corresponding to $\mathrm{NiO}_{2}$ (COD 9016308) and Lithium silicates (COD $2310662 \mathrm{Li}_{2} \mathrm{SiO}_{3}, \mathrm{COD} 9007747 \mathrm{Li}_{2} \mathrm{Si}_{2} \mathrm{O}_{5}$ ) have appeared (Figure 1). The formation of silicate phases may be caused by the presence of silicon atoms in the volume of the film or by partial interaction between the silicon wafer and deposited lithium oxide structures.

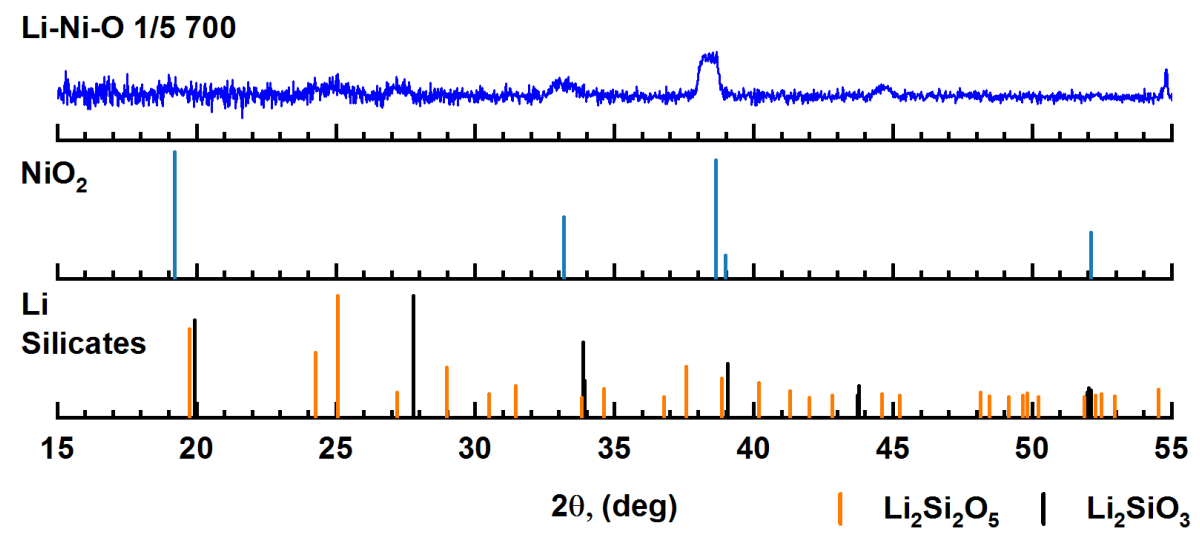

Figure 1 XRD pattern of Li-Ni-O 1/5 700 (silicon wafer) 


\subsection{Electrochemical activity}

To determine the electrochemical activity of the initial stainless steel and stainless steel with deposited films, the cyclic voltammetry $(\mathrm{CV})$ was used. Anode $(3.5 \mathrm{~V}, \mathrm{I}=1.5 \mu \mathrm{A})$ and cathode $(2.95 \mathrm{~V}, 2 \mu \mathrm{A})$ peaks are presented in CV curves (Figure 2a). Since the initial substrate doesn't contain lithium ions, the observed peaks may be caused by formation and dissolution of solid electrolyte interface film. On the CV curves of samples with deposited films after calcination at $600^{\circ} \mathrm{C}$ and higher temperature, two additional peaks are presented - anode $(4.19 \mathrm{~V})$ and cathode $(3.72 \mathrm{~V}$ ) (Figure $2 \mathrm{~b}$ ). The intensity of current at $3.72 \mathrm{~V}$ (cathode curve) enhances with increasing of calcination temperature from 600 to $800{ }^{\circ} \mathrm{C}$ during $\mathrm{CV}$ scans of lithiated transitional metals (Ni, $\mathrm{Co}, \mathrm{Mn}$ ) oxides, the increase of current in the 4.15-4.25V range is observed, and it characterizes the oxidation process $\mathrm{Ni}^{2+} / \mathrm{Ni}^{3+} / \mathrm{Ni}^{4+}$. A shoulder near $4.2 \mathrm{~V}\left(\mathrm{Ni}^{4+} / \mathrm{Ni}^{3+}\right)$ and increase of current at $3.65-3.75 \mathrm{~V}\left(\mathrm{Ni}^{3+} / \mathrm{Ni}^{2+}\right)$ is related to reduction processes [14]. The area under anode peaks is much higher than the area under cathode peaks; thus, pronounced irreversibility is observed.

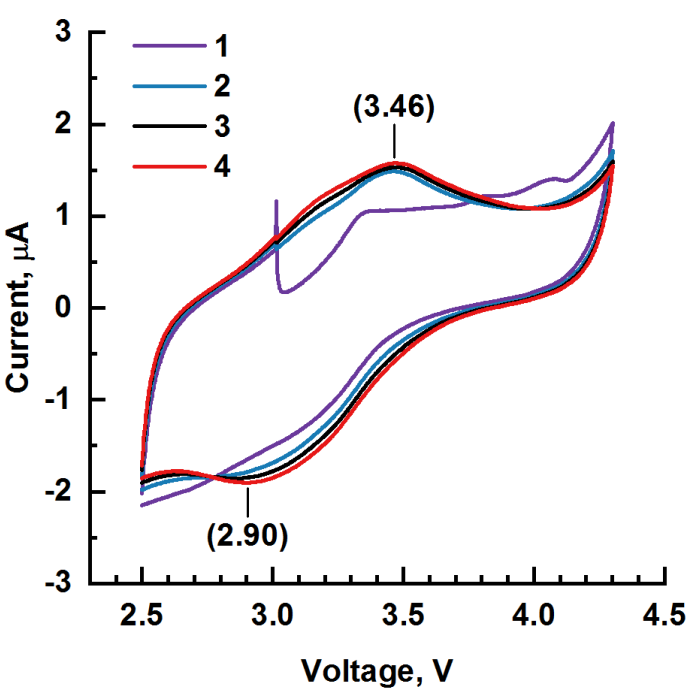

(a)

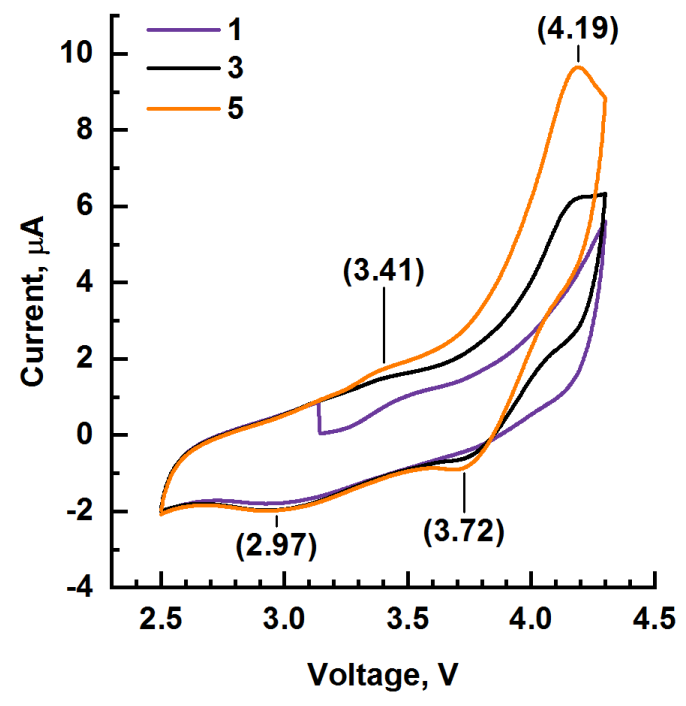

(b)

Figure 2 Cyclic voltammetry curves of initial stainless steel substrate (a) and Li-Ni-O 1/10 600 (b)

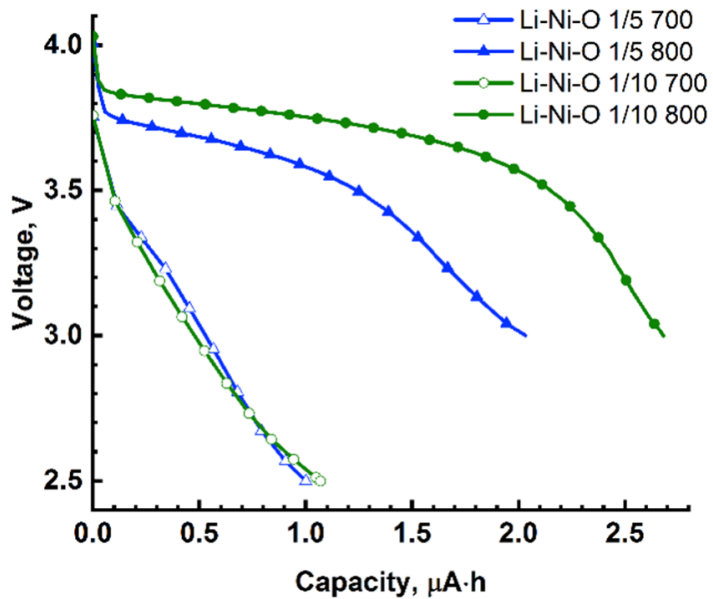

(a)

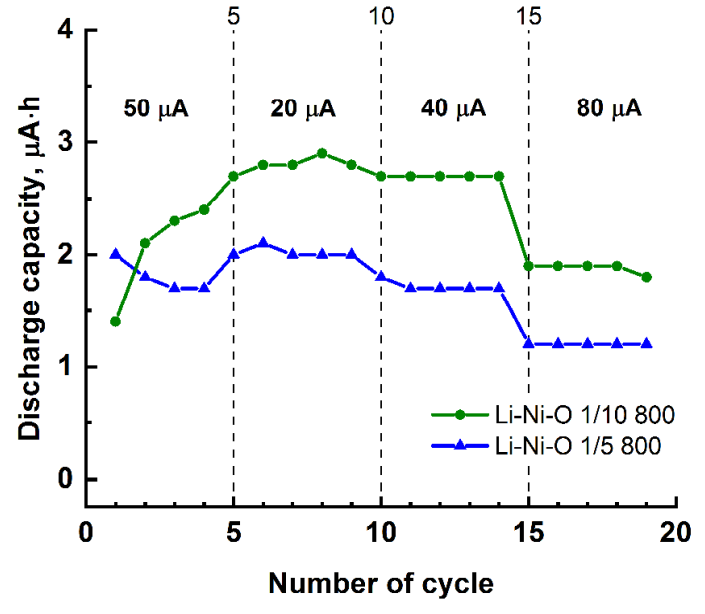

(b)

Figure 3 Voltage change during discharge at $20 \mu \mathrm{A}$ current (a) and effect of discharge current on capacity of Li-Ni-O calcinated films (b) 
The shape of discharge (discharge current, $l_{d}=20 \mu \mathrm{A}$ ) curves of electrodes calcinated at $700{ }^{\circ} \mathrm{C}$ and lower was almost linear (Figure 3a). The capacity of calcinated Li-Ni-O 1/5 and Li-Ni-O 1/10 electrodes was close to $1 \mu \mathrm{Ah}$. With an increase of treatment temperature, the form of discharge curves started to resemble the shape of $\mathrm{LiNiO}_{2}$ discharge curves and capacity have augmented. We suppose that $\mathrm{Li}-\mathrm{Ni}-\mathrm{O}$ 1/10 800 have higher capacity than Li-Ni-O 1/5 800 due to higher content of nickel atoms and therefore electrochemically active phase. The films with higher nickel content (number of nickel oxide cycles deposition in supercycle) should be studied to obtain high discharge capacity.

At first five charge/discharge cycles the small increase of capacity was observed for both series of samples what correlates with augmentation of cathode peaks on cyclic voltammetry curves. During subsequent cycles, the discharge capacity stabilized and diminished with an increment of discharge current (Figure 3b).

Table 4 Electrode active layer properties

\begin{tabular}{|c|c|c|c|c|c|c|c|}
\hline \multirow{2}{*}{ Sample } & \multirow{2}{*}{$\begin{array}{l}\mathrm{H}, \\
\mathrm{nm}\end{array}$} & \multirow{2}{*}{$\begin{array}{c}\rho, \\
\mathrm{g} / \mathrm{cm}^{3}\end{array}$} & \multicolumn{2}{|c|}{$I_{D}$} & \multirow{2}{*}{$\begin{array}{l}\mathrm{C}_{\mathrm{f}} \\
\mu \mathrm{Ah}\end{array}$} & \multirow{2}{*}{$\begin{array}{c}\mathrm{C}_{\mathrm{vol}}, \\
\left(\mu \mathrm{Ah} \cdot \mu \mathrm{m}^{-1} \cdot \mathrm{cm}^{-2}\right)\end{array}$} & \multirow{2}{*}{$\begin{array}{c}\mathrm{C}_{\mathrm{m}} \\
\mathrm{mAh} / \mathrm{g}\end{array}$} \\
\hline & & & $\mu \mathbf{A}$ & C & & & \\
\hline Bulk $\mathrm{LiNiO}_{2}$ & 100 & 4.6 & - & 0.5 & 19 & 97 & 210 \\
\hline Bulk LiCoO 2 & 100 & 4.8 & - & 0.5 & 15 & 74 & 155 \\
\hline $\begin{array}{c}\mathrm{Li}_{1.2} \mathrm{CoO}_{3.5}[5] \\
3.0 \div 4.1 \mathrm{~V}\end{array}$ & 60 & 2.8 & 0.5 & 0.35 & 3.3 & 27 & 96 \\
\hline Li-Ni-O 1/5 800 & 74 & - & 20 & 10 & 2 & 13 & - \\
\hline Li-Ni-O 1/10 800 & 58 & $\approx 2.7$ & 20 & 7.4 & 2.7 & 23 & 83 \\
\hline
\end{tabular}

Note: $\mathrm{C}_{\mathrm{f}}$ - full capacity of active layer with $1.6 \mathrm{~cm}$ diameter and $\mathrm{H}$ thickness; $\mathrm{C}_{\mathrm{m}}$ - weight capacity; $\mathrm{C}_{\mathrm{vol}}$ - volume capacity; $\rho$ - density of active layer.

The observed volume and weight relative capacities for both samples were lower than reported for LithiumCobalt-Oxide ALD film [5], but in the present study, the discharge currents with higher density were used (Table 4). The capacity of Li-Ni-O $1 / 10800$ diminished from $23 \mu \mathrm{Ah} \cdot \mu \mathrm{m}^{-1} \cdot \mathrm{cm}^{-2}(83 \mathrm{mAh} / \mathrm{g})$ to $17 \mu \mathrm{Ah} \cdot \mu \mathrm{m}^{-1}$. $\mathrm{cm}^{-2}(61 \mathrm{mAh} / \mathrm{g})$ with the increase of discharge current from $20 \mu \mathrm{A}(7.4 \mathrm{C})$ to $80 \mu \mathrm{A}(40 \mathrm{C})$.

\section{CONCLUSION}

Thin lithium-nickel oxide films were synthesized with the use of ALD method. The number of nickel oxide layers deposited in supercycles varied from 5 to 10 . Adding nickel oxide cycles stabilized the lithium oxide film and hinder its interaction with air atmosphere. The deposited films were amorphous. Calcination at $700{ }^{\circ} \mathrm{C}$ and higher lead to film crystallization. The reflexes of $\mathrm{NiO}_{2}$ and lithium silicates were found on XRD patterns. The silicates may present due to incomplete removal of precursor molecules during synthesis or cause by the interaction of lithium oxide structures with the silicon substrate.

Both $\mathrm{Li}-\mathrm{Ni}-\mathrm{O}$ 1/5 T and Li-Ni-O 1/10 T exhibited electrochemical activity which increased with nickel content and calcination temperature. The estimated value of $\mathrm{Li}-\mathrm{Ni}-\mathrm{O} 1 / 10800$ capacity was $61 \mathrm{mAh} / \mathrm{g}$ at high discharge current (40C).

\section{ACKNOWLEDGEMENTS}

The research was conducted under the financial support of the Russian Science Foundation grant (project No. 18-73-10015). 


\section{REFERENCES}

[1] KHAN Y., OSTFELD A. E., LOCHNER C. M., PIERRE A., ARIAS A. C. Monitoring of Vital Signs with Flexible and Wearable Medical Devices. Advanced Materials. 2016. vol. 28, no 22, pp. 4373-4395. https://doi.org/10.1002/adma.201504366.

[2] WANG X. R., YUSHIN G. Chemical vapor deposition and atomic layer deposition for advanced lithium ion batteries and supercapacitors. Energy \& Environmental Science. 2015. vol. 8, no 7, pp. 1889-1904. https://doi.org/10.1039/c5ee01254f.

[3] ZHU R. J., REN Y., GENG L. Q., CHEN T., LI L. X., YUAN C. R. Properties of all-solid-state lithium-ion rechargeable batteries deposited by rf magnetron sputtering. Modern Physics Letters B. 2013. vol. 27, no 22, pp. 5. https://doi.org/10.1142/s021798491350156x.

[4] DONDERS M. E., KNOOPS H. C. M., KESSELS W. M. M., NOTTEN P. H. L. Remote Plasma Atomic Layer Deposition of Thin Films of Electrochemically Active LiCoO2. ECS Transactions. 2011. vol. 41, no 2, pp. 321-330. https://doi.org/10.1149/1.3633683.

[5] DONDERS M. E., ARNOLDBIK W. M., KNOOPS H. C. M., KESSELS W. M. M., NOTTEN P. H. L. Atomic Layer Deposition of LiCoO2 Thin-Film Electrodes for All-Solid-State Li-lon Micro-Batteries. Journal of the Electrochemical Society. 2013. vol. 160, no 5, pp. A3066-A3071. https://doi.org/10.1149/2.011305jes.

[6] MIIKKULAINEN V., RUUD A., OSTRENG E., NILSEN O., LAITINEN M., SAJAVAARA T., FJELLVAG H. Atomic Layer Deposition of Spinel Lithium Manganese Oxide by Film-Body-Controlled Lithium Incorporation for Thin-Film Lithium-Ion Batteries. Journal of Physical Chemistry C. 2014. vol. 118, no 2, pp. 1258-1268. https://doi.org/10.1021/jp409399y.

[7] PUURUNEN R. L. Surface chemistry of atomic layer deposition: A case study for the trimethylaluminum/water process. Journal of Applied Physics. 2005. vol. 97, no 12, pp. 52. https://doi.org/10.1063/1.1940727.

[8] MALYGIN A. A., DROZD V. E., MALKOV A. A., SMIRNOV V. M. From V. B. ALESKOVSKII'S "Framework" Hypothesis to the Method of Molecular Layering/Atomic Layer Deposition. Chemical Vapor Deposition. 2015. vol. 21, no 10-12, pp. 216-240. https://doi.org/10.1002/cvde.201502013.

[9] NILSEN O., MIIKKULAINEN V., GANDRUD K. B., OSTRENG E., RUUD A., FJELLVAG H. Atomic layer deposition of functional films for Li-ion microbatteries. Physica Status Solidi a-Applications and Materials Science. 2014. vol. 211, no 2, pp. 357-367. https://doi.org/10.1002/pssa.201330130.

[10] KOSHTYAL Y., NAZAROV D., EZHOV I., MITROFANOV I., KIM A., RYMYANTSEV A., LYUTAKOV O., POPOVICH A., MAXIMOV M. Atomic Layer Deposition of NiO to Produce Active Material for Thin-Film LithiumIon Batteries. Coatings. 2019. vol. 9, no 5, pp. 16. https://doi.org/10.3390/coatings9050301.

[11] NAZAROV D., EZHOV I., MITROFANOV I., LYUTAKOV O., MAXIMOV M. Y. The Use of the TMA as Stabilizing Reagent for the Li-O System Obtained by Atomic Layer Deposition. Key Engineering Materials. 2019. vol. 822. pp. 787-794. https://doi.org/10.4028/www.scientific.net/KEM.822.787.

[12] IIDA Y. Evaporation of Lithium Oxide from Solid Solution of Lithium Oxide in Nickel Oxide. Journal of the American Ceramic Society. 1960. vol. 43, no 3, pp. 171-172. https://doi.org/10.1111/j.1151-2916.1960.tb14336.x.

[13] YLILAMMI M. Monolayer thickness in atomic layer deposition. Thin Solid Films. 1996. vol. 279, no 1-2, pp. 124130. https://doi.org/10.1016/0040-6090(95)08159-3.

[14] CHONG S. K., LIU Y. N., YAN W. W., CHEN Y. Z. Effect of valence states of Ni and Mn on the structural and electrochemical properties of Li1.2NixMn0.8-xO2 cathode materials for lithium-ion batteries. Rsc Advances. 2016. vol. 6, no 59, pp. 53662-53668. https://doi.org/10.1039/c6ra09454f. 